\title{
Effects of substrate heating on the microstructure and hardness of TiB/Ti6Al4V-ELI during laser in-situ metal deposition
}

\author{
PM Lekoadi', M Tlotleng, ${ }^{1,2}$ BN Masina ${ }^{1, *}$ \\ ${ }^{1}$ Council for Scientific and Industrial Research (CSIR), Manufacturing, National Laser Centre, Laser Enabled Manufacturing Group, \\ PO Box 395, Pretoria 0001, South Africa \\ 2 Department of Mechanical Engineering Science, University of Johannesburg, Auckland Park Campus, Johannesburg 2012, South Africa \\ Email:bmasina@email.ac.za
}

\begin{abstract}
This work investigated the influence of heating temperature $\left({ }^{\circ} \mathrm{C}\right)$ on the microstructure and microhardness of TiB/Ti6Al4V-ELI composite clads that were produced via in-situ alloying using laser metal deposition technique. The samples were produced on a Ti6 $\mathrm{Al} 4 \mathrm{~V}$ base plates which were heated at different temperatures $\left(25^{\circ} \mathrm{C}, 200^{\circ} \mathrm{C}, 300^{\circ} \mathrm{C}, 400^{\circ} \mathrm{C}\right.$ and $\left.500^{\circ} \mathrm{C}\right)$ before they were characterised for microstructure and hardness. It was found that the TiB/Ti6Al4V-ELI sample that was produced on a non-pre-heated base plate was characterized by TiB particles and had the lowest hardness of $511 \pm 66 \mathrm{HV}$. Base plate heating resulted in the formation of TiB whiskers that were dispersed within the titanium matrix. $200^{\circ} \mathrm{C}$ led to a microstructure with clusters of TiB whiskers hence it had an increased hardness of $651 \pm 40 \mathrm{HV}$. A fine microstructure with homogeneous distribution of the TiB whiskers was obtained at $500^{\circ} \mathrm{C}$ base plate heating temperature and had hardness of $565 \pm 14 \mathrm{HV}$.
\end{abstract}

\section{Introduction}

Laser metal deposition (LMD) is a type of directed energy deposition (DED) laser additive manufacturing (AM) technology that involves manufacturing of metal components directly from three-dimensional (3D) computer aided design (CAD) by adding powder materials layer-by layer. ${ }^{1,2} \mathrm{LMD}$ has attracted more attention in the aerospace, automotive, and biomedical industries during the last few decades due to the advantages it offers which include manufacturing of geometrically accurate metal parts, repairing of damaged or worn-out parts, ability to produce functional coating, generation of small heat affected zone and material savings. ${ }^{3-6}$ The LMD process involves feeding of powder materials, supported by shielding gas (usually argon), directly into a melt pool, produced by an accurately focused laser beam on a pre-placed base plate. LMD is famously known to process various materials such as steel, titanium and its alloys, nickel based super alloys and others.

Ti6Al4V (also known as Ti64) is the most processed titanium alloy. In recent years, Ti6Al4V has been strengthened by alloying with different ceramics such as TiB, TiC and WC, into its bulk matrix, to produce titanium matrix composites (TMCs). ${ }^{7-11}$ TMCs are rendered attractive in various industries which include aerospace, biomedical, automotive, petrochemical and military. ${ }^{12-15}$ Their success is attributed to their high strength, low density, good wear resistance, excellent corrosion behaviour and stability at high temperatures. ${ }^{11,16,17}$ In the aerospace industry, TMCs are used as latent materials for critical structural parts. ${ }^{7,11,12} \mathrm{TiB}_{2}$ is one of most promising, effective and widely used ceramic because of its good chemical affinity with titanium and outstanding thermal stability. ${ }^{7,11,18,19}$ Moreover, the similarity in density and thermal of expansion coefficient of $\mathrm{TiB}_{2}$ to that of titanium matrix enhance the bonding during reinforcement. ${ }^{20-21}$
LMD process is accompanied by rapid heating and fast cooling rates, which lead to thermal gradients within the built parts. This results in thermally induced residual stresses and formation of inhomogeneous microstructures, ${ }^{22,23}$ part cracking, delamination and distortion during manufacturing. These defects typically lead to premature part failure. ${ }^{17,22,24,25}$ A method to cure residual stresses during manufacturing and overcome these occurrences is to perform continuous base plate heating during material deposition. According to literature, base plate heating reduces thermal gradients within the built part, which improve the microstructure and result in minimal or complete elimination of residual stresses. ${ }^{17,22,26-29}$ In order to understand the role of base plate heating during laser processing, on the improvement of mechanical properties and residual stresses reduction, it is important to understand the role of substrate heating temperature during manufacturing on the microstructural evolution and resulting hardness of TiB/Ti6Al4V composite. The effects are studied in this paper.

The influence of substrate heating temperature on microstructure and mechanical properties of $\mathrm{H} 13$ tool steel parts manufactured by selective laser melting (SLM) was investigated by Martens et al. (2016). Cube samples of $10 \mathrm{~mm}$ x $10 \mathrm{~mm}$ x10 mm dimension were produced on a base plate that was pre-heated to temperature ranges of $100-400^{\circ} \mathrm{C}$. The cube samples were produced using laser power of $170 \mathrm{~W}$, scanning speed in the range $400-800 \mathrm{~mm} / \mathrm{s}$ and layer thickness of $30 \mu \mathrm{m}$. It was found that when the substrate was heated to $400^{\circ} \mathrm{C}$, a homogeneous microstructure was achieved and had improved mechanical properties compared to the as-produced parts. A hardness in the range 650-700 $\mathrm{HV}$ and ultimate tensile strength of $1965 \mathrm{MPa}$ were reported to be better than those of conventionally manufactured and heat-treated counterparts. It was further reported that substrate temperature of $100^{\circ} \mathrm{C}$ and $200^{\circ} \mathrm{C}$ softened the material while $300^{\circ} \mathrm{C}$ and $400^{\circ} \mathrm{C}$ led to a stronger and uniform material. 


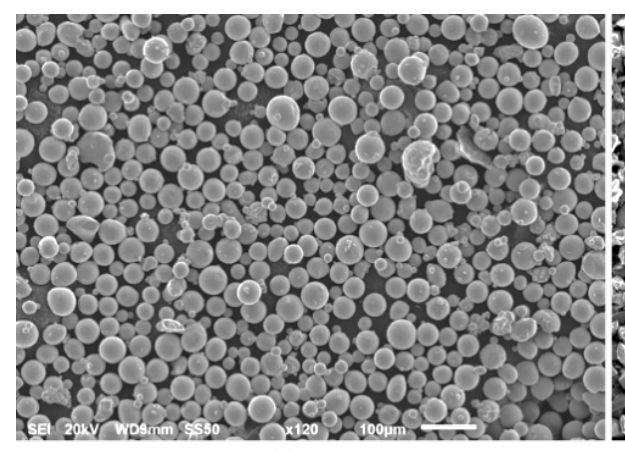

(a)

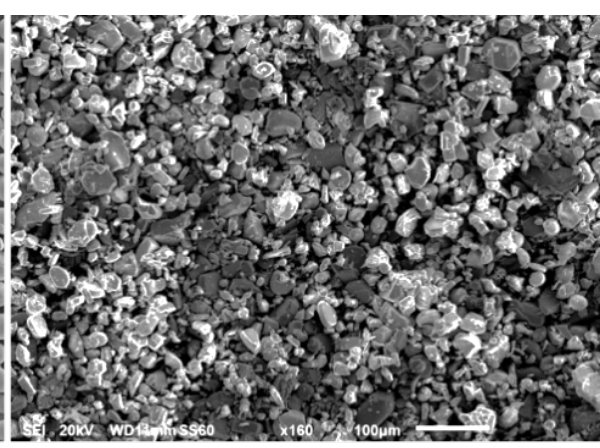

(b)

Figure 1: SEM images of the (a) Ti6Al4V-ELI powder and (b) $\mathrm{TiB}_{2}$ particles

In another study, Zhou et al. (2008) investigated the microstructural characteristics of laser deposited WC/Ni on a mild steel base plate that was heated at $900^{\circ} \mathrm{C}$. A laser power in the range $20-50 \mathrm{~kW}$ and scanning speed in the range $2000-3000 \mathrm{~mm} / \mathrm{min}$ were employed, and they found that $900^{\circ} \mathrm{C}$ led to a crack-free component and further improved the bonding between the substrate and deposited samples. A similar study by Liu and DuPond (2004) evaluated the microstructure and hardness properties of titanium aluminide matrix composite produce on laser engineered net shaping (LENS) technique. Specimens of dimension $13 \mathrm{~mm} \times 13 \mathrm{~mm}$ x $8 \mathrm{~mm}$ were manufactured with laser power in the range $170-340 \mathrm{~W}$, scanning speed in the range $4-17 \mathrm{~mm} / \mathrm{s}$, hatch distance $0.254 \mathrm{~mm}$ and standoff distance $152.4 \mathrm{~mm}$ on a Ti6Al4V base plate. The Ti6Al4V base plate was heated at temperatures in the range $400-500^{\circ} \mathrm{C}$. It was observed that crack-free deposits can be fabricated by preheating the substrate in this temperature range $450-500^{\circ} \mathrm{C}$. At this condition, they observed un-melted particles of $\mathrm{TiC}$ and $\mathrm{Ti}_{2} \mathrm{AlC}$ carbides which were distributed within the matrix. The hardness of the deposited composite was more than twice that of Ti6Al4V. The increase in hardness was attributed to the presence of the un-melted $\mathrm{TiC}$ and $\mathrm{Ti}_{2} \mathrm{AlC}$ carbides.

Recently, a study by Johnson and Palmer (2019) reported that preheating is required during DED of molybdenum on a steel plate. Using laser power, scanning speed, hatch distance nozzle stand-off and spot size of 250-900 W, 254-635 mm/s, $31.8 \mathrm{~mm}$ and $4 \mathrm{~mm}$, respectively, as processing parameters, it was found that pre-heating at $100-150^{\circ} \mathrm{C}$ allowed for adhesion of the depositing material and resulted in fewer defects. However, the samples displayed cracking along grain boundaries attributed to the low pre-heating temperature. Finally, a related but different study by Vasinota et al. (2007) investigated the effect of pre-heating during DED of stainless steel. It was found that pre-heating of the base plate at a temperature of $400^{\circ} \mathrm{C}$ led to the reduction of residual stresses by $40 \%$ at a temperature of $400^{\circ} \mathrm{C}$. Jendrezewski et al. 2004 found that pre-heating at $500^{\circ} \mathrm{C}$ reduced the amount of distortion on $\mathrm{X} 10 \mathrm{Cr} 13$ chromium steel and resulted in a crack-free parts.

The reviewed studies show that different materials respond differently toward pre-heating temperature. In addition, base plate pre-heating during LMD of TiB/Ti6Al4V- extra low interstitials (ELI) is rarely reported in literature. Hence, it is important to understand the role of pre-heating temperature on microstructures and mechanical properties such as hardness of LMD TiB/Ti6Al4VELI composite. This study focused on investigating the effect of pre-heating on microstructure and hardness properties of LMD of TiB/Ti6Al4V-ELI composite.

\section{Experimental Procedure}

\subsection{Materials}

Spherical grade 5, pre-alloyed Ti6Al4V-ELI with particle size distribution in the range 20-60 $\mu \mathrm{m}$ (supplied by TLS Technik $\mathrm{GMbH} \& \mathrm{Co}$, Bitterfeld, Germany) and $\mathrm{TiB}_{2}$ particles with size in the range $-140+325$ mesh (supplied by Stanford Advance Material) were used during deposition. Scanning electron microscope (SEM) images of the Ti6Al4V-ELI and $\mathrm{TiB}_{2}$ particles are presented in Figure 1.

Figure 1(a) shows that the particles of the Ti6Al4V-ELI powder were spherical and smooth, with no porosity observed. It must be noted that LMD process requires good flow properties of the powders for homogeneous spreading and good densification. Figure 1(b) shows that the $\mathrm{TiB}_{2}$ particles were irregular in shape. The samples were deposited on $100 \mathrm{~mm}$ x $100 \mathrm{~mm}$ x $6 \mathrm{~mm}$ Ti6Al4V base plate.

\subsection{Methods}

All test samples were manufactured on an IPG fibre laser (1073 nm wavelength) processing system which was integrated on a KUKA robot and 3-way nozzle. A GTV powder system (D-57629), equipped with two powder feed hoppers was used to deliver the Ti6Al4V-ELI and $\mathrm{TiB}_{2}$ powders through the carrier gas during deposition. The Ti6Al4V-ELI and $\mathrm{TiB}_{2}$ were placed inside the hoppers and powder flow rates of $5 \mathrm{rpm}$ and $1.2 \mathrm{rpm}$ were used, respectively, to deliver the powders during deposition. The powder carrier gas was transferred at $1.5 \mathrm{l} / \mathrm{min}$ during the deposition process. Argon gas was used as a shielding gas (protective gas) to prevent oxidation on the manufactured samples. Laser power of $1500 \mathrm{~W}$, scanning speed of $0.5 \mathrm{~m} / \mathrm{min}$, gas flow rate of $12 \ell /$ min and beam diameter of $2 \mathrm{~mm}$ were used as the processing parameters during deposition for all the samples.

The Ti6Al4V base plate was subjected to sand blasting to prepare it for deposition. Before the deposition process, the Ti6A14V base plate was heated on a heating stage to various temperatures of $200^{\circ} \mathrm{C}, 300^{\circ} \mathrm{C}, 400^{\circ} \mathrm{C}$ and $500^{\circ} \mathrm{C}$, respectively. The temperature was measured using a Raytek PM Plus pyrometer (Santa Cruz, CA USA). Long single line track of approximately $40 \mathrm{~mm}$ were deposited for every temperature. All samples were left to cool 
to room temperature inside the heating stage before taken for metallographic preparations and observations.

\subsection{Metallographic preparation and characterization}

The deposited samples were cut perpendicular to the deposition direction on a Struers Labotom-5 cutting machine using a Struers high quality titanium cut-off wheel (20S25). The samples were then mounted using an AMP 50 automatic mounting press machine. AKA Resin Phenolic SEM black conductive resin was used to mount all samples. The mounted samples were mechanically ground with Struers Tetrapol-25 grinding and polishing machine. Silicon carbide (SiC) grinding papers with grit sizes of 80,320 , 1200 and 4000 were used for grinding the samples which were later surface finished by polishing to a mirror finish using Diapro MDMol $3 \mu \mathrm{m}$ diamond suspension and colloidal silica $0.04 \mu \mathrm{m}$ OP-S suspension for 3 minutes. The specimens were etched with Kroll's reagent, a solution containing $100 \mathrm{ml} \mathrm{H}_{2} \mathrm{O}, 1-3 \mathrm{ml} \mathrm{HF}$ and 2-6 ml $\mathrm{HNO}_{3}$.

The metallographically prepared and etched samples were observed for microstructure using an Olympus BX51M Optical microscope and Joel JSM-6010PLUS/LA SEM. To observe full view of the microstructure, microstructural images were taken using various magnifications. Hardness measurements were performed using Matsuzawa Seiko Vickers model MHT-1 micro-hardness machine. All measurements were done using a diamond tip indenter while applying a force of $0.3 \mathrm{kgf}$ and dwell time of $10 \mathrm{~s}$. For all samples, three hardness patterns were measured, and the average was calculated as the hardness of the material.
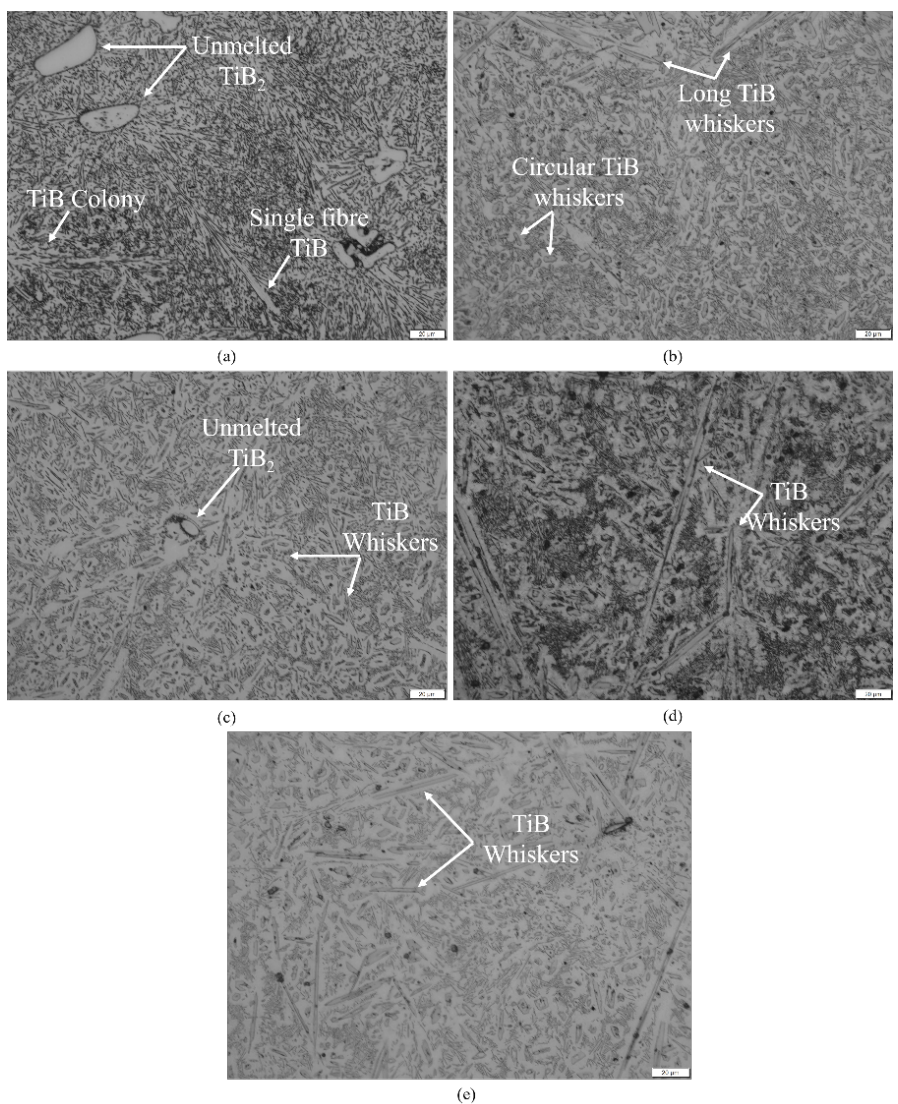

Figure 2: Optical images of the samples (a) non-pre-heated, (b) $200^{\circ} \mathrm{C}$, (c) $300^{\circ} \mathrm{C}$, (d) $400^{\circ} \mathrm{C}$ and (e) $500^{\circ} \mathrm{C}$

\section{Results}

\subsection{Optical microstructure}

Optical microstructures $(20 \mu \mathrm{m})$ of the non-pre-heated and preheated samples of the TiB/Ti6Al4V-ELI composite are presented in Figure 2. The samples were pre-heated at $200^{\circ} \mathrm{C}, 300^{\circ} \mathrm{C}, 400^{\circ} \mathrm{C}$ and $500^{\circ} \mathrm{C}$, respectively.

Figure 2(a) shows the microstructure of the non-pre-heated sample. It was observed that $\mathrm{TiB}$ particles were formed due to the in-situ reaction between $\mathrm{Ti}$ and $\mathrm{B}$. These $\mathrm{TiB}$ particles were uniformly dispersed throughout the microstructure, either as single fibres or in colonies as can be seen in Figure 2(a). Due to the high cooling rates associated with the LMD process, the TiB particles are sharp and thin. To explain and understand the formation of these TiB particles, a Ti-B binary phase diagram is presented in Figure 3.

The binary phase diagram shows the formation of three particulates which are $\mathrm{TiB}, \mathrm{Ti}_{3} \mathrm{~B}_{4}$ and $\mathrm{TiB}_{2}$. It can also be seen that the weight percentage of $\mathrm{B}$ required for the formation of $\mathrm{TiB}$ and $\mathrm{TiB}_{2}$ is approximately $18 \mathrm{wt} \%$ and $30 \mathrm{wt} \%$, respectively. This implies that the presence of $18 \mathrm{wt} \%$ B promote the reaction with Ti to form TiB. A study by Verma et al. (2021) showed that the reaction paths given by Equation 1 lead to the formation of TiB particle during laser AM.

$T i+T i B_{2} \rightarrow 2 T i B$

The reaction given above (Equation 1) explain the observation of $\mathrm{TiB}$ particles, instead of $\mathrm{TiB}_{2}$ on the microstructure of the non-pre-heated sample. The microstructure of the non-preheated sample was also characterized by un-melted $\mathrm{TiB}_{2}$ powder particles as shown in Figure 2(a). The un-melted $\mathrm{TiB}_{2}$ powder particles were few found at certain regions of the microstructure. It must be noted that the presence of the unmelted $\mathrm{TiB}_{2}$ particles was observed on the microstructures of all the samples. The presence of these $\mathrm{TiB}_{2}$ particle was attributed to insufficient energy density to fully melt all the $\mathrm{TiB}_{2}$ powder. It must be noted that the interaction between a laser beam and metallic powder relies on the powder's absorptivity, sizes and physical properties. ${ }^{35}$ The energy density $\mathrm{E}\left(\mathrm{J} / \mathrm{m}^{3}\right)$ is given by the Equation 2 below:

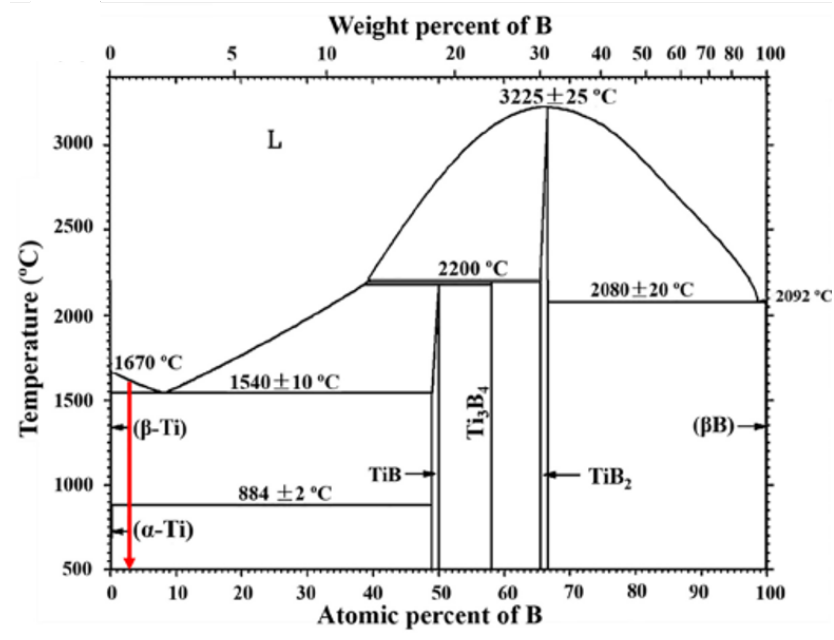

Figure 3: Ti-B binary phase diagram [Cai et al. 2019] 


$$
E=\frac{P}{v \cdot h \cdot t}
$$

Where $\mathrm{P}(\mathrm{J} / \mathrm{s})$ is the laser power, $\mathrm{v}(\mathrm{m} / \mathrm{s})$ is the scanning speed, $\mathrm{h}(\mathrm{m})$ is the hatch spacing and $\mathrm{t}(\mathrm{m})$ is the layer thickness. ${ }^{36}$ The observation of un-melted $\mathrm{TiB}_{2}$ particles after laser processing were reported in literature. ${ }^{37,38}$

It can be seen from Figure 2(b) that pre-heating at $200^{\circ} \mathrm{C}$ resulted in a different microstructure from the non-pre-heated sample (Figure 2a). In fact, pre-heating at $200^{\circ} \mathrm{C}$ led to the formation of $\mathrm{TiB}$ whiskers instead of the $\mathrm{TiB}$ particles that were observed on the microstructure of the non-pre-heated sample (Figure 2a). This observation was attributed to the pre-heating method that led to temperature control during cooling of the sample. The formed TiB whiskers were dispersed throughout the microstructure and showed two types of morphologies, namely, long needle-like and circular. It is important to note that the circular TiB whiskers were dominant over the needle shaped TiB whiskers. The morphology and distribution of the TiB whiskers will be discussed in detail in the next section using high resolution SEM microstructures.

Pre-heating at $300^{\circ} \mathrm{C}$ did not lead to any observable microstructural change from the $200^{\circ} \mathrm{C}$ pre-heated sample (Figure $2 \mathrm{~b}$ ) as can be seen in Figure 2(c). However, a slight variation between on the dispersing of the $\mathrm{TiB}$ whiskers was observed. The $300^{\circ} \mathrm{C}$ sample showed a slight loosely packed $\mathrm{TiB}$ whiskers as compared to the closely packed $\mathrm{TiB}$ whiskers of on the $200^{\circ} \mathrm{C}$ sample. This observation might be due to growth of the $\mathrm{TiB}$ whiskers due to the difference in pre-heating temperatures. Pre-heating at $400^{\circ} \mathrm{C}$ resulted in growth of the $\mathrm{TiB}$ whiskers as can be seen in Figure 2(d). Moreover, $400^{\circ} \mathrm{C}$ pre-heating led to a refined microstructure. Lastly, the microstructure of the sample that was pre-heated at $500^{\circ} \mathrm{C}$ is presented in Figure 2(e). It can be clearly seen that pre-heating at $500^{\circ} \mathrm{C}$ produced a transformed fine microstructure, accompanied by growth of the TiB whiskers.

\subsection{SEM microstructures}

To study further the microstructure of the $\mathrm{TiB} /$ Ti6Al4V-ELI composite samples in detail, SEM was used to obtain high resolution images at a higher magnification. The obtained SEM images of the non-preheated and pre-heated samples is shown in Figure 4.

Figure 4(a) shows that the microstructure of the nonpre-heated sample was composed of $\mathrm{TiB}$ rich regions (white regions). Some of these $\mathrm{TiB}$ rich were parallel to each other, while other were that were clustered in one region. A similar type of microstructure was reported by Cai et al. (2019), after using SLM to process Ti6Al4V and $1 \mathrm{wt} \% \mathrm{TiB}_{2}$ and attributed the formation of $\mathrm{TiB}$ regions to insufficient time for $\mathrm{TiB}$ to grow due to high solidification rate induced by the laser during the SLM process. It is important to note that $\mathrm{TiB}$ whiskers were not present in the microstructure of the non-pre-heated sample as can be seen in Figure 4(a).
The un-melted $\mathrm{TiB}_{2}$ particles that were observed on the optical microscope images (Figure 4a) were clearly visible, however, a partially melted $\mathrm{TiB}_{2}$ particles were observed on the microstructure of the sample as shown in Figure 4(a). The presence of the unmelted and partially melted $\mathrm{TiB}_{2}$ particles was explained on the optical microstructures above.

The microstructure of the sample that was pre-heated at $200^{\circ} \mathrm{C}$ is presented in Figure 4(b). Three types of phases which are represented by different colors, namely, grey, white and dark were observed on the microstructure of this sample. Based on the observation made by Xu et al. (2018) after XRD analysis, the white, grey and dark phases can be identified as $\alpha, \beta$, and TiB whiskers, respectively. Since Ti6Al4V-ELI is $\alpha+\beta$ alloy, the presence of these two phases after deposition was expected and is supported by the finding of $\mathrm{Xu}$ et al. (2018). Furthermore, since pre-heating was used to control the cooling rate, the presence of these two phases were expected without the formation of martensite $\alpha$. Preheating at $200^{\circ} \mathrm{C}$ led to the formation of two types $\mathrm{TiB}$ whiskers with different morphologies as can be seen in Figure 3(b). The first type was elongated needle-shaped that were distributed on some regions of the microstructure of the sample. The average length of these elongated needle shaped TiB whiskers was calculated as $\sim 72.48 \mu \mathrm{m}$. The second type was short irregular shaped TiB whiskers that were dominant and distributed homogeneously on

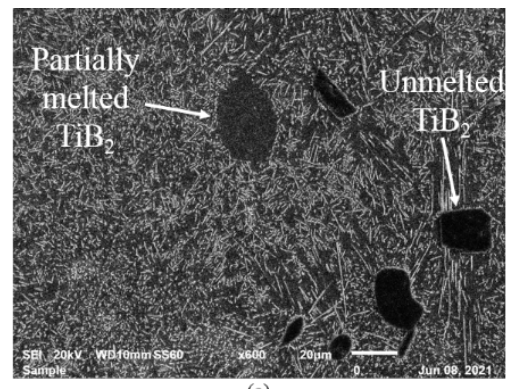

(a)

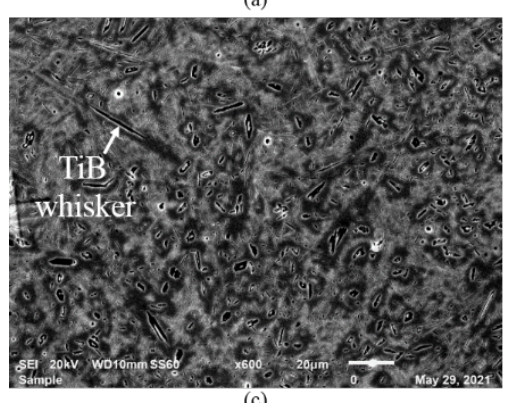

(c)

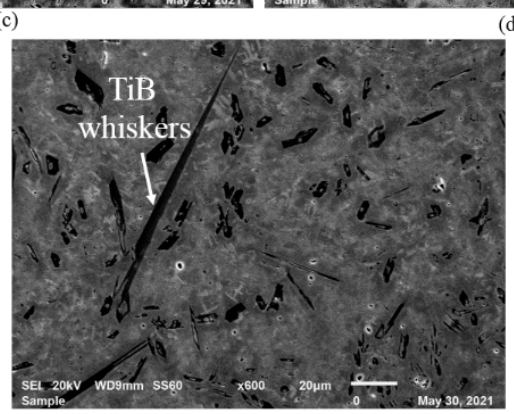

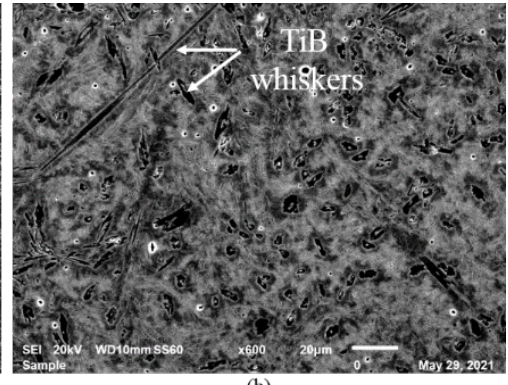

(b)

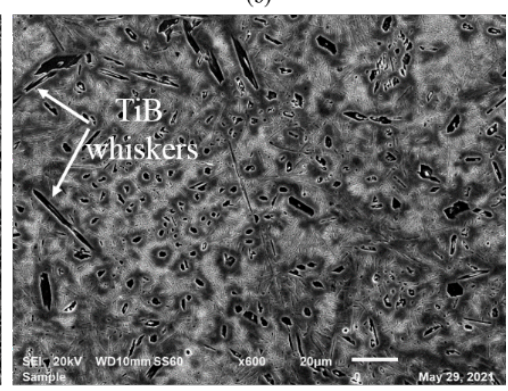

Figure 4: SEM images of the samples (a) non-pre-heated, (b) $200^{\circ} \mathrm{C}$, (c) $300^{\circ} \mathrm{C}$, (d) $400^{\circ} \mathrm{C}$ and (e) $500^{\circ} \mathrm{C}$ 


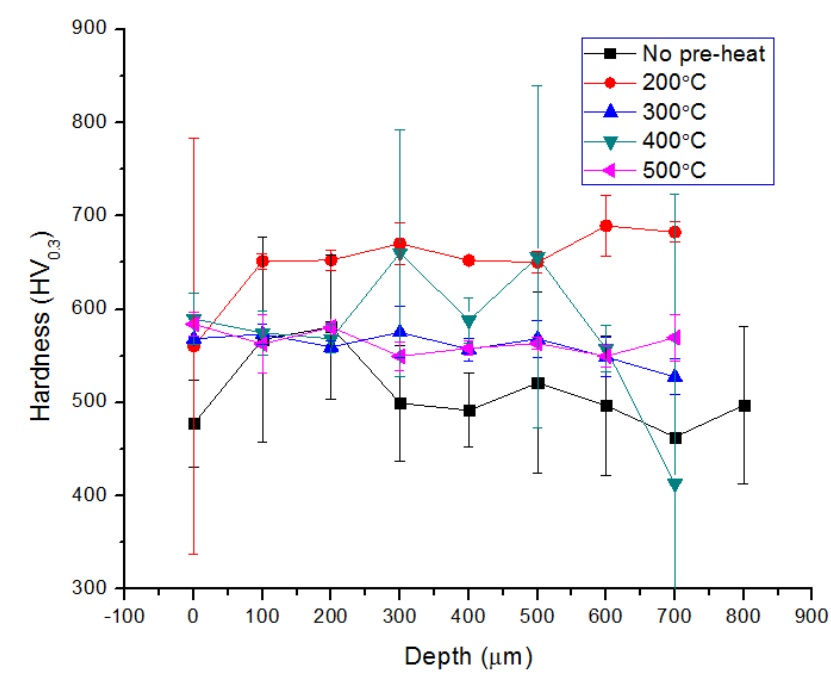

Figure 5: Hardness of the non-pre-heated and pre-heated samples

the microstructure of the sample. The average length of the short TiB was calculated as $\sim 15.04 \mu \mathrm{m}$. A Similar type of TiB whiskers were reported in literature..$^{23,37}$

There was no observed microstructural change after pre-heating at $300^{\circ} \mathrm{C}$. The three phases together with the two types of $\mathrm{TiB}$ whiskers were present. The elongated and short TiB whiskers on the microstructure of the $300^{\circ} \mathrm{C}$ pre-heated samples was calculated as $\sim 54.42 \mu \mathrm{m}$ and $\sim 6.06 \mu \mathrm{m}$. Pre-heating at $400^{\circ} \mathrm{C}$ led to grain growth. This is attributed to the growth of $\alpha$ and $\beta$ phases as can be seen in Figure 4(d). Moreover, both the elongated and short TiB whiskers were observed to be thicker (Figure 4d) than the one on the microstructure of the $200^{\circ} \mathrm{C}$ (Figure $4 \mathrm{~b}$ ) and $300^{\circ} \mathrm{C}$ (Figure $4 \mathrm{c})$ pre-heated samples, respectively, which was an indication of grain growth. The elongated TiB whiskers were calculated to be $\sim 54.64 \mu \mathrm{m}$ while $\sim 11.55 \mu \mathrm{m}$ was obtained for the short whiskers. The microstructure of the sample that was pre-heated at $500^{\circ} \mathrm{C}$ is presented in Figure $4(\mathrm{e})$. Pre-heating at $500^{\circ} \mathrm{C}$ produced a drastically changed microstructure. The clustering of the TiB whiskers was observed to have reduced and properly arranged. Moreover, the size of the TiB whiskers was increased. The elongated and short whiskers was calculated to be $\sim 66.81 \mu \mathrm{m}$ and $\sim 28.36 \mu \mathrm{m}$.

\subsection{Hardness}

The hardness profiles and average hardness of the non-preheated and pre-heated samples are shown in Figure 5 and Table 1, respectively.

Table 1: Average hardness of the samples

\begin{tabular}{cc}
\hline Temperature $\left({ }^{\circ} \mathbf{C}\right)$ & Hardness $(\mathbf{H V})$ \\
\hline No pre-heat & $511 \pm 66$ \\
200 & $651 \pm 40$ \\
300 & $560 \pm 15$ \\
400 & $576 \pm 93$ \\
500 & $565 \pm 14$ \\
\hline
\end{tabular}

Figure 5 and Table 1 shows that the sample that was not pre-heated resulted in the lowest hardness profile and average hardness value. The low hardness was attributed to the absence of the TiB whiskers that was observed on the microstructure of the sample (Figure 4a).
On the other hand, pre-heating at $200^{\circ} \mathrm{C}$ gave the highest hardness profile and average hardness as can be seen in Figure 5 and Table 1. The high hardness on this sample was attributed to the high concentration of dispersed TiB whiskers that were observed on the microstructure of this sample (Figure $4 \mathrm{~b}$ ). A slight decrease in hardness was observed after pre-heating at $300^{\circ} \mathrm{C}$ as presented in Table 1. This observation was not expected since the $200^{\circ} \mathrm{C}$ and $300^{\circ} \mathrm{C}$ samples resulted in similar microstructures. There was not variation in hardness observed on the sample that was pre-heated at $400^{\circ} \mathrm{C}$ and $500^{\circ} \mathrm{C}$, respectively. This observation was not expected since the $300^{\circ} \mathrm{C}$ (Figure $3 \mathrm{c}$ ), $400^{\circ} \mathrm{C}$ (Figure $3 \mathrm{~d}$ ) and $500^{\circ} \mathrm{C}$ (Figure $3 \mathrm{e})$ samples resulted in noticeable microstructural difference.

\section{Discussion}

TiB/Ti6Al4V composites were produced with LMD technique on a pre-heated Ti6Al4V base plate in order to evaluate the effect of preheating on microstructural evolution and hardness and hardness property. It is well known that LMD process is associated with high heating and cooling rates that induced thermal gradients on the manufactured parts, which alters the microstructure, hence, pre-heating is necessary to improve the microstructure and mechanical properties. This study has shown that pre-heating plays and important role in the microstructural formation and hardness properties. The sample that was not pre-heated gave different microstructural characteristics compared to the pre-heated samples. However, both pre-heating and non-preheating showed formation of TiB which was proof that in-situ reaction between Ti6Al4V and $\mathrm{TiB}_{2}$ took place. The in-situ reaction was between $\mathrm{Ti}$ and $\mathrm{TiB}_{2}$ to form $\mathrm{TiB}$ according to the reaction $\mathrm{Ti}+\mathrm{TiB}_{2} \rightarrow 2 \mathrm{TiB}^{34,35}$

Even though $\mathrm{TiB}$ rich regions were observed on the microstructure of the non-preheated sample (Figure 3a), formation of the TiB whiskers could not occur. The absence of TiB whiskers implied that their formation requires pre-heating of the base plate during deposition. Most importantly, the absence of the TiB whisker on the microstructure of the non-pre-heated sample led to low hardness of $511 \pm 66 \mathrm{HV}$ compared to the hardness of the preheated samples (Table1). Studies by Cai et al. (2019) and Li et al. (2021) reported that $\mathrm{TiB}$ whiskers are characterised by high hardness. When preheating was carried out at $200^{\circ} \mathrm{C}$, two types of TiB whiskers were formed in the Ti6Al4V matrix (Figure 2b, 3b). The formation of the TiB whiskers resulted in a highest hardness of $651 \pm 40 \mathrm{HV}$ due to the clustering of them throughout the entire microstructure. The high hardness on the sample was also supported by needle-like shaped and short TiB whiskers which gave highest average length of $\sim 72.48 \mu \mathrm{m}$ and $15.04 \mu \mathrm{m}$, respectively, compared other samples. The formation of the TiB whiskers was attributed to the pre-heating temperature that was used.

When a pre-heating temperature of $300^{\circ} \mathrm{C}$ was used, a slight microstructural change in terms of the size of the $\mathrm{TiB}$ whiskers occurred (Figure 3c). A length reduction of the needle-like shaped and short TiB whisker to $\sim 54.42 \mu \mathrm{m}$ and $\sim 6.06 \mu \mathrm{m}$ was observed. This implied pre-heating at $300^{\circ} \mathrm{C}$ reduced the size of the $\mathrm{TiB}$ whiskers. The reduction in length of the TiB whiskers led to a decrease in hardness to $560 \pm 15 \mathrm{HV}$. As the pre-heating temperature was increased to $400^{\circ} \mathrm{C}$, a finer microstructure was obtained (Figure 3d). Moreover, thickening of TiB whiskers was obvious. 
The length of the needle-like shaped and short TiB whiskers were calculated as $54.64 \mu \mathrm{m}$ and $\sim 11.55 \mu \mathrm{m}$, respectively. Even though the length of the long needle shaped TiB whiskers remained the same, the increase in length of the short TiB whisker supported the thickening of the whiskers that was observed on the microstructure of the sample (figure $3 \mathrm{~d}$ ). The thickening of the $\mathrm{TiB}_{2}$ whiskers was accompanied by a slight increase in hardness to $576 \pm 93 \mathrm{HV}$.

The sample that was pre-heated at $500^{\circ} \mathrm{C}$ (Figure 4e) showed a fine microstructure compared to the $200^{\circ} \mathrm{C}, 300^{\circ} \mathrm{C}$ and $400^{\circ} \mathrm{C}$ samples (figures $4 \mathrm{~b}, 4 \mathrm{c}, 4 \mathrm{~d}$ ). Microstructural refinement as observed, with clustering and arrangement of the $\mathrm{TiB}$ whiskers highly improved. In addition, pre-heating at $500^{\circ} \mathrm{C}$ also led to the growth of the TiB whiskers (Figure 3e). However, the hardness remained similar at $565 \pm 14 \mathrm{HV}$. The observed similarity in hardness was not expected since an obvious microstructural change was observed. From the above-mentioned results, it can be said that pre-heating at would be an ideal condition for the pre-heating of Ti6Al4V base plate, since it produced a fine microstructure with thicker and longer TiB whiskers properly arranged.

\section{Conclusion}

This study undertook to understand the effect of base plate preheating on the microstructure and hardness of LMD built TiB/ Ti6Al4V-ELI samples. The microstructures and hardness of the non-pre-heated and pre-heated samples were characterized. The results conclusively proved the hypothesis that pre-heating is suitable for the production of $\mathrm{TiB}$ whiskers that can act as reinforcing materials. The following conclusion were made:

- LMD of TiB/Ti6Al4V-ELI on a non-pre-heated plate produces a microstructure with TiB particles only.

- Base plate pre-heating at $200^{\circ} \mathrm{C}, 300^{\circ} \mathrm{C}, 400^{\circ} \mathrm{C}$ and $500^{\circ} \mathrm{C}$ produces a microstructure with $\mathrm{TiB}$ whiskers that act as reinforcing material.

- Formation of the TiB whiskers result in increased hardness.

- A fine microstructure with proper arrangement of the TiB whiskers was obtained by pre-heating at $500^{\circ} \mathrm{C}$.

- The hardness increases with increasing heating temperature until $400^{\circ} \mathrm{C}$ and then decreases slightly.

\section{Acknowledgments}

The authors would like to thank the Department of Science and Innovation (DSI) for funding through the Collaborative Program in Additive manufacturing (CPAM). The Council for Scientific and Industrial Research is thanked for laboratory equipment support.

\section{References}

1. Azarniya A, Colera X, Mirzaali M, Sovizi S, Bartolomeu F, Wegkowski M, Wits W, Yap C, Ahn J, Miranda G, Silva F, Hosseini H, Ramakrishna S and Zadpoor A 2019 J. Alloy and Compd. 804 163-91
2. Scott J, Gupta N, Weber C, Newsome S, Wohlers T and Caffrey T 2012 Sci. Tech. Pol. Inst. 3 1-32

3. Zhong C, Liu J, Zhao T, Schopphoven T, Fu J, Gasser A and Schleifenbaum J 2020 Appl. Sci. 10 1-12

4. Abdulrahman K, Akinlabi E, Mahamood R, Pityana S and Tlotleng M 2018 Mater. Today 5 19738-46

5. Zadpoor A 2018 Materials 11 1566-76

6. Manhood R, Akinlabi E, Shukla M and Pitjana S 2013 Mater. Des. 50 656-666

7. Wang J, Li L, Lin P and Wang J 2018 Opt and Laser Tech. 105 195-206

8. Farayibi P, Abioye T, Kennedy A and Clare A 2019 j. Manuf. Proedia 45 429-37

9. Rahoma H, Chen Y, Wang X and Xiao S 2015 J. Alloy Compd. $627415-22$

10. Xiao L, Lu W, Yang Z, Qin J, Zhang D, Wang M, Zhu F and Ji B 2008 Mater. Sci. Eng. A 491 192-98

11. Hayat M, Singh H, He Z and Cao P 2019 Composites A 121 418-38

12. Lu J, Qin J, Chen Y, Zhang Z, Lu W and Zhang D 2010 J. Alloys Compds 490 118-23

13. Huang L, Wang L, Qian M and Zou J 2017 Scr. Mater. 141 133-7

14. Cui C, Hu B, Zhao L and Liu S 2011 Metals 7 1-17

15. Li H, Jia D, Yang Z, Liao X, Jin H, Cai D and Zhou Y 2021 Mater. Sci Eng. A 801 1-10

16. Li W, Yang Y, Liu J, Zhou M, Li S, Wen S, Wei Q, Yan C and Shi Y 2017 Acta Mater. 136 90-104

17. Hu Y and Cong W 2018 Ceramics International 44 20599-612

18. Pouzet S, Peyre P, Corny C, Castelnau O, Baudin T, Brisset F, Colin C and Gadaud P 2016 Mater. Sci Eng. A 677 171-181

19. Zhao L, Cui C, Liu S, Zhao L and Li N 2016 Mater. Sci Eng. A 663 8-16

20. Zhou W, Kamata K, Dong M and Nomura N 2021 Powder Tech. 382 274-83

21. Wang J, Liu S, Fang Y and He Z 2020 Inter. J. Adv. Manuf. Tech. 108 2453-66

22. Maly M, Holler C, Skalon M, Meier B, Koutny D, Pichler R, Sommitsch C and Palousek D 2019 Materials 12 2-13

23. Martens R, Vrancken B, Holmstock N, Kinds Y, Kruth J and Humbeeck J 2016 Physics Procedia 83 882-90

24. Zhou S, Huang Y, Zeng X and Hu Q 2008 Mater. Sci. Eng. A $480564-72$

25. Xu R, Liu B, Liu Y, Cao Y, Guo W and Nie Y 2018 Materials 11 2-13

26. Abdulrahman K, Akinlabi E and Mahamood R 2019 Chapter 8, 165-183

27. Vora P, Mumtaz K, Todd I and Hopkinson N 2015 Addit. Manuf. 7 12-19

28. Buchbinder D, Meiners W, Pirch N, Wissenbach K and Schrage J 2014 J. Laser Appl. 26

29. Sander j, Hufenbach J, Giebelern L, Wenronck H, Kuhn U and Eckert J 2016 Mater. Design 89 335-341

30. Liu W and Dupont J 2004 Metall. Mater. Trans. A 35 1133-40

31. Johnson J and Palmer T 2019 Inter. J. Refr. Metal and Hard Mater. 84 1-6

32. Vasinota A, Beuth J and Griffith M 2007 J. Manuf. Sci. Eng. $129101-9$

33. Jendrzejewski R, Sliwinski G, Krawczuk M and Ostachowicz W 2004 Comp. and Struc. 82 653-58

34. Cai C, Radoslaw C, Zhang J, Yan Q, Wen S, Song B and Shi Y 2019 Powder Tech. 342 73-84

35. Verma P, Warghane S, Nichul U, Kumar P and Dhole A 2021 Mater. Character. 172 1-11

36. Herzog D, Syda V, Wycisk E and Emmelmann C 2016 Acta Mater. $117371-92$

37. Sahay S, Ravichandran K and Atri R 1999 Mater. Research 14 4214-23

38. Poopola A, Phume L, Pityana S and Aigbodion V 2016 Surf. Coating Tech. 285 161-70

39. Panda K and Chadran K 2003 Metall. Mater. Trans. A 153 1-17

40. Yue N, Lu L and Lai M 1999 Comp. Struct. 47 691-94 